\title{
Analysis of Open Source Software in Enterprise Informatization
}

\author{
Chunli $\mathrm{Bi}^{1}, \mathrm{Li} \mathrm{Zhao}^{2}$, Jinsong Liu' and Huaying Shu' \\ 'School of Economics and Management, Beijing University of Posts and \\ Telecommunications, Beijing 100876, P.R.Chinabicl@163.com liujinsong@bupt.edu.cn \\ shuhy@bupt.edu.cn \\ ${ }^{2}$ School of Law, Renmin University of China, Beijing 100872, P.R. China \\ zhaoli2830@sina.com
}

\begin{abstract}
Enterprise informatization experiences three phases information islet modeling, intranet modeling and integrated enterprise modeling. The traditional market failure argument suggests that innovation is characterized by high investment and low copy cost, and firms have difficulty in internalizing the fruits of their innovative effort. Thus, technology firms are seeking more patents, expanding their scope and overhauling their business models around intellectual property. Yet paradoxically, with the progress and development of information technology, open source software (OSS) plays an important role in expanding enterprise informatization. For example, Linux is developed quickly by this open way. Some firms have found the ways of making money by opening up their treasure-chest of innovation and sharing it with others. The rise of open-source software is one example.

In this article, the author introduces a model of OSS based on its network effects to understand how the enterprises decide their activities in this open market competition. This article describes the inherent reasons of open source movement from the view of the oligopoly structure. At the same time, this article analyses the effect of leader enterprise and follower enterprise on market structure and the different activities of these enterprises after the source has been opened. Finally, we make suggestions that companies at the leading edge are often in such a strong position that they do need the support of down-streams companies to broaden their technologies successfully and to decrease their risks in order to leverage the value of the technological portfolio. On the other hand, this article suggests that follower enterprises have incentive to take part in the development of open-source software only when the market has grown up.
\end{abstract}

Keywords: Open source software, OSS model, Enterprise normalization

Please use the following format when citing this chapter:

Bi, C.. Zhao, L.. I.iu, J., Shu, 11., 2007, in II'IP' International liederation for Information Processing. Volume 254. Rescarch and Practical Issues of Interprise Information Systems II Volume 1, eds. 1.. Xu. Tjoa A.. ( haudhry S. (Beston: Springer), pp. 669-676. 


\section{INTRODUCTION}

While the informationization is unceasingly progressing, how to integrate different enterprise information resources into enterprise's comprehensive competence is getting more and more important. As early as in 1980s, Alvin Toffler, an American renowned sociologist, has proposed in his famous work "Third Tide" that the humanity has experienced the agriculturalization tide, the industrialization tide. Now, the third tide - informationization tide will be forthcoming. He also has forecasted scientifically that the information revolution will bring the humanity a new huge change, and the digital network will be the kernel of the third tide [1].

Enterprise informationization experiences three phases -information islet modeling, intranet modeling and integrated enterprise modeling. Integrated enterprise modeling adopts various information-applied modes, e.g., internet, E-Commerce (EC), Enterprise Resources Planning (ERP), Product Data Management (PDM), Customer Relation Management (CRM), Computer Integration Manufacture System (CIMS) etc. In order to adapt to the highly effective and fast development of the world economics, science and technology, the application technologies in open source code software which emphasize on implementing open computation and open standard foundation are rapidly developing, and also causing the giant echoes in the field and has partially succeed. On January 11, 2005, IBM announced that more than 500 software patents would be put into the opening source code community and would be used for free. Afterwards, Nokia, Ret Hat, Computer Associates and Sun also successionally put their own software patents in open source community. Forrester Research Corporation estimated that there are about $50 \%$ of enterprises around the worldwide are using open source software [2].

The goal of enterprise is maximizing the shareholder's value. The way of open sources seems to be paradoxical. Multinational corporations invest massive manpower and financial resources to focus on the improving enterprise core competence through the patent competition. Their basic logic is the one who win the cutting edge technology position will win the market. Tom Bethell said "people who own resources may benefit from opening their resources to other people [3], but it highly depends on the market structure where enterprises are located. According to different competition degree, the western economists classify the market into the four categories: Perfect Competition Market, Monopolistic Competition Market, Oligopoly Competition Market and Complete Monopoly Market.

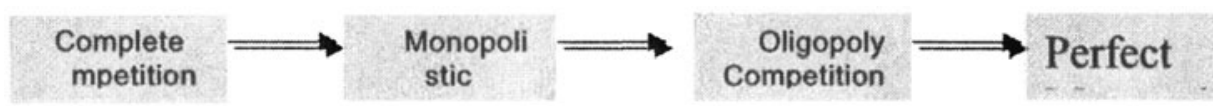

Figure 1. The Classify of Market Structure

In the real market situation, both complete competition and perfect monopoly are very rare. Moulton Karman and Nanci Schwartz [4] proposed that the market structure that is mostly advantageous to the technology innovation should be positioned between complete competition and perfect monopoly, namely monopolistic competition market and oligopoly market. But under the background of 
economic globalization, both Chinese and overseas experts hold the opinion that the most beneficial market for the competition among different patents should surely be oligopoly market [5].

Under the assumption of oligopoly market, this article will mainly analyze those inherent factors which is relevant to Open Source Movement and caused by the enterprise informationization, Furthermore, study on how leader enterprise and follower enterprise will react on the market scale selection and decision making strategy will also included in this article.

\section{MECHANISM ANALYSIS ON THE OPEN SOURCE MOVEMENT IN THE OLIGOPOLY MARKET}

Open Source has different definitions, one of them which comes from the Open Source initiator (OSI) was defined as "it refers to the software with its own source code being widely used by the public; the use, revision and distribution of the software can be realized without any license fee[6]. Here one thing should be noticed that the open-source code software usually has the copyright. The license of OSS usually contains some limits: the original status of the open-source code software should be protected strictly; software author's identification data should be marked clearly; or related development activity can be somehow limited, etc.

This open-source movement can be traced back to a software engineer named Richard Stallman in 1980s, he proposed a so-called "copy left" movement, and founded the free software foundation ("FSF") which aimed at opposing the limitation usage of copyright and the patent of the software. A huge amount of free software had been issued according to those provisions in GPL. According to the GPL provision, "free software" refers to "the free software", not refer to software charge free. In his opinion, the software should be used and revised by the public as freely and equally as like they use the Holy Bible. But this did not mean no cost would be incurred[6].

Researching on the OSS market, we can easily find that almost all kinds of open source code were backed by technical strategies alliance, which is controlled by several enterprises. For example, one open source software like the LAMP framework, are composed of Linux - open-source operating system, Apache - opensource page server, MySQL--- open-source database, except for that, some script languages like PHP, Perl, Python etc. also play an important role in the LAMP framework. Compared with J2EE framework (Java) led by IBM, Sun, and the dot Net framework (C\#) led by Microsoft, the triangle competition situation appeared. In 2005 , IBM provided 500 patents covering 14 regions freely. The main service targets of these patents are the Linux operating system software users and the Apache homepage service software users. These two kinds of software have already occupied certain market share. One of the reasons why IBM would firmly support the Linux operating system is that IBM wants to weaken the hegemonic position of Microsoft (Microsoft Corp., MSFT) in this field.

The perdurability of the oligopoly in technology market depends on the potential entry barriers to market [7]. Clarkson and Miller (1989) suggested that entry barriers were composed of seven sources, respectively are distinct scale of economy, 
demand of capital, possession of critically important resources, patents and licenses, advertisement, product differentiation and variety of pattern, and superfluous throughput. Most of these oligopoly enterprises leverage some of these barriers to protect themselves, which is distinctly characteristic by keeping other enterprises away, for example, patent and license. The patents of IBM exceeded two thousand and nine hundred in 2005 and IBM has continued to keep the patent championship for 13 years. In the year 2004, IBM earned over one billion dollars licenses fee through his over 40 thousands ownership of patents [8].

Arrow thought that existing market forces would restrain the motivation of technology innovation, because new products' introduction competed not only with the products of other manufacturers in the niche market, but also cannibalized with their own existing products. The more market shares the manufacturer possessed, the stronger the latter effect showed. Just because Arrow Substitute Effect functioned are popular applied, innovation may harm more on manufacturer with leading position in the market. The leading manufacturer therefore will be inclined to stay on the current championship and not pursue further advancement in technology and product innovation [9]. Kelly, the director of IBM's Intellectual Property Department, told the real reason why they opened the original codes: IBM was afraid if they had too much protection of intellectual properties, they would face the risk of weakening innovation gradually. Patent essentially is used to help to recover one kind of balance, but if the balance is much too far away in certain direction, the industry will be ruined, and then IBM will be ruined.

From Arrow's Substitute Effect, we can easily find that oligopoly market structure is not always advantageous to oligarchs. Under the market environment of high-tech and continual innovation, oligarchs prefer not to supplant all the small companies. On the contrary, these fresh bloods can benefit them in promoting the innovation and also keeping their innovation motivation and consciousness. But, those big companies who want to open part of patents resources is not equal to they will give up all of the patents. If they want to open their patents from very beginning, why do they spend large amount of money in researching/developing and applying for patents? Under the environment of realistic economic market, manufacturers who own patents do not always win the market monopoly. For enterprises, turning patents into business application and production successfully is the final goal. Furthermore, the existing high and new technology enterprise has not yet been able to catch the monopoly position only through only one single patent. It must have core patents or basic patents. Only in this way, enterprises have influences in the related technology field.

In the game theory model, which was adopted by K\&Y to explore the uncertainty and Spillover Effect leading to RJV (Research Joint Venture), he suggested that the company which first successfully implemented R\&D, cannot assure itself holding the market completely [10]. He suggested that only successfully applied for the core patent, can they truly achieve the" winner" situation. The patents they provided for free are only those fringe patents in that technology field, or the patents with which the current oligarchs can hold the future development trend in control [3]. 


\section{MODEL ANALYSIS}

Through the analysis of the actual OSS, we find that only when these open source software reach a considerate scale, or win a number of users, can the follower enterprises participate in the second development or the market expanding. Take the Linux for example; although the Linux source code just occupies 3\%-5\% of the OSS source code, but its wide range of users make it on leading and fundament position in the entire open source software field. In an open source community, the enterprises that adopt the open source software are numerous, and among these enterprises, which adopt the open source software and take active part in it are also not small amount. According to the above analysis, we know that most of the OSS market structures are oligopoly. For facility, we suppose two enterprises, the OSS leader enterprise A (one of the oligopolies) and the OSS follower enterprise B (other small enterprises). The model for discussion is confined to the sub game perfect Nash equilibrium. The detailed assumption is listed below:

1. The information is perfect, e.g. all information the enterprise acquired is credible, avoiding from the un-trusty threaten;

2. The technology adopted in the OSS has attained a certain portion in the market;

3. All enterprises are equal-efficient in the R\&D progress;

4. A certain tech is monopolized by several oligopolies. But in the OSS, only enterprise A opens, while only the enterprise B follows;

5. The market sales volume is indicated as the volume related to the OSS tech.

\subsection{The Model Analysis of OSS on Market Scale}

Supposing that before the OSS, the market share of A and B is respectively marked as $i_{A}$ and $i_{B}$, and $i_{A>0}, i_{B}=0$.

The sales volume of $\mathrm{A}$ is $Q_{1}, Q_{\text {is the total market sales volume, thus }}$

$$
\mathrm{i}_{\mathrm{A}}=\frac{Q_{1}}{Q}
$$

By the use of opening source code, technology improved, enterprise B gets increased sales volume at: $\Delta Q \geq 0, \quad i_{B} \geq 0$. Meanwhile, the increased sales volume of enterprise $B$ substantially leads to technology market share of enterprise $A$ increased, that is:

(1) It means that the sales volume of other enterprises is decreasing if the total volume is stable. Then:

$$
i_{A}^{\prime}=\frac{Q_{i}+\Delta Q}{Q} \geq i
$$

(2) If the total volume has been increased due to new users and sales volume of other enterprises remain unchanged, then: 


$$
i_{A}^{\prime \prime}=\frac{Q_{i}+\Delta Q}{Q+\Delta Q} \geq i
$$

It's benefit all technical market, both enterprise $A$ and $B$ through opening source code. Enterprise A expands their developed technology to new application users, which will therefore provide a good opportunity to develop their core patent to control market. At the same time, enterprise B also strengthens its technology capability and broadens technical market. Of course, Enterprise A must be able to control the whole technical trend. It will be very dangerous if it is out of control, wasting their investment will be the result in the situation of losing control. On the other hand, enterprise $B$ is also taking a risk because it may have to give up some their own technology advantages by following the technology of Enterprise A.

\subsection{The "Prisoner's Dilemma" Analysis, Enterprise Strategy Selection Analysis in Opening Source Code Situation}

From the above analysis, open source code increases the whole market sale volume and profit amount. In order to simplify model, we can set assumptions that the market will keep a basic and stable profit before enterprise $A$ opens source code. We assume the basic profit is zero to simplify thereafter comparison with that enterprise A opened source code. We also assume that the increased profit are 4 after Enterprise A opened its source to the market. If enterprise A opened the OSS, enterprise B followed to use OSS, the total profit will increase to 4 , enterprise $A$ and $B$ shared the gross profit, that is $(2,2)$. If Enterprise $B$ refused to follow, the increased profit will be zero according to formula (2), (3) $\Delta Q=0$, it means the gross profit of the market increased zero. Similarly, the increased market profit will also be zero on the condition of Enterprise A's no open and B's no follow. If enterprise A refused to open the OSS, enterprise B still wanted to follow this technology, Enterprise would invest research \& development cost in this new technology. No doubt that Enterprise B will reduce its profit. Therefore the whole game will be as follows:

Table 1. The Game of Enterprise $A$ and Enterprise B

\begin{tabular}{|l|l|l|l|}
\hline \multicolumn{2}{|c|}{} & \multicolumn{2}{|l|}{ Enterprise B } \\
\cline { 3 - 4 } \multicolumn{2}{|c|}{} & Entering & No entering \\
\hline \multirow{2}{*}{ Enterprise A A } & Opening & $(2,2)$ & $(0,0)$ \\
\cline { 2 - 4 } & No opening & $(0,-2)$ & $(0,0)$ \\
\hline
\end{tabular}

The above diagram shows two Nash Equilibriums, namely, enterprise A opened source and enterprise B follow, or conversely, enterprise A did not open source and enterprise B did not follow. Obviously, enterprise A and B will choose the strategy to maximize their own profits, that is to say, Nash Equilibriums (enterprise A opened and enterprise $\mathrm{B}$ followed) is an optimum one. Accordingly, whatsoever purposes that 
oligarchic enterprises conceived, either for promoting innovations or for snatching market shares, open source offers an invaluable opportunity for small followers to learn advanced technologies and explore more practice in the technology market.

The actual open source movement also substantiated correctness of this model. Taking Linux for example, at the inception stage, some big companies including IBM, Compaq and Sun willingly contributed their own source codes to jointly fight with their common rival - Microsoft, which in the end led to the birth of Linux. Today, there are two mainstream Linux enterprises, i.e. RedHat and TurboLinux and 309 Linux solutions across the world. Some Chinese software enterprises have also been involved in Linux development, such as Linux software platform providers: Red Flag, Co-Create, CS2C, TurboLinux China and SWL. Except for strong momentum from the world's mainstream Linux enterprises, they also need the participation from more and more enterprises to pursue their combat against Microsoft. Therefore, they choose to open source codes through General Public License (GPL), which will allow Chinese Linux enterprises have more opportunity to get themselves involved in the technology market and therefore integrated their specific resources to possess one position in Linux's coming day.

\section{CONCLUSIONS}

Open source is benefit to increasing social welfare and expanding market in the technology field. Both oligarchic enterprises and small followers will create new values in this movement. Just as some scholars such as Levin H. Campbell said, patent system is simply a kind of second-best efficiency mechanism [11].

Under oligopoly competition market, industry-leading enterprises will also take the responsibility to consider the future development of industry and dig out the potential market requirement [12]., while they snatch the monopoly profits. However, in order to lower risk, they may intentionally disclose to their rivals or publicize a portion of their R\&D information, or open their source codes so as to achieve future development and maximize their long-term profits. For the follower, which is relative weak in technology, open source undoubtedly offers them a premium opportunity to get acquainted with the development trend of advanced technologies. They can keep their technical development strategies on the right track and will not diverge from the mainstream. However, huge following risk (surrendering their own technology) is also a problem, which they should carefully consider in advance.

For most Chinese software enterprises, as there is little technical leadership in the industry, they should take sensible strategy when facing the massive open source movement. On the one hand, they should take full use of these advanced technologies; on the other hand, they should take prudent approaches with in-depth analysis so that they will not spent huge amount of resources in research of open source movement, and at the same time they surrender their advantages. 


\section{ACKNOWLEDGEMENTS}

This paper is funded from "The Fund for $\mathrm{PhD}$ Candidate Paper of Beijing Science \& Technology Committee" with the fund No. ZZ0640.

\section{REFERENCES}

1. X. Pu and Z. Si, Network Economic (Machinery Publish House: 2006).

2. Anonymous, the new opportunity for Chinese software, CNII (2005). http://www.enet.com.cn/article/2005/1229/A20051229488111.shtml (Accessed July 14, 2007).

3. J.D. Gwartney, R.L. Stroup, and R.S. Sobel, Economics Private and Public Choice (CITIC Publish House), p.34.

4. J. Ma, Re-clearance of Relationship between Technology Innovation and Market Structure, Technology Economic. pp.19-20, (1996).

5. R. Dai and S. Gao, The Effect of Market Structure on Patent Race, Forecasting. Number 2, (2003).

6. K. Coar, The Open Source Definition (Annotated) (2006). http://www.opensource.org/docs/definition.php(Accessed July 14, 2007).

7. J. Liu, Reform on Monopoly Industry - analysis based on network perspective (Economic Management Publish House: Beijing, 2005), pp.26.

8. Anonymous, the strike of IBM to Windows (2005).

9. http://live.intozgc.com/049/49624.html(Accessed July 14, 2007)

10. J. Liu, Reform on Monopoly Industry - analysis based on network perspective (Economic Management Publish House: Beijing, 2005).

11. S. Gao and $\mathrm{X}$. Jiang, Patent Competition Theory - pre-empt right model remark, Management Engineering Journal. Volume 3, pp.47-51, (2003).

12. Anonymous, Survey: An open secret, The Economist. Volume 377, Number 8449, p.17, (2005).

13. R.C. Levin, A.K. Klevorick, R.R. Nelson, and S.G.. Winter, Appropriating the returns from industrial research and development, Brookings Papers on Economic Activity. pp.783-820, (1987).

14. G.D. Fraja, Strategic spillovers in Patent Race, International Journal of Industrial Organization. pp.139-146, (1993). 